\title{
PROPERTIES AND OPTIMAL MANUFACTURING CONDITIONS OF CHICKEN FEATHERS THERMOPLASTIC BIOCOMPOSITES
}

\author{
X. Colom ${ }^{1}$, A. Rahalli ${ }^{1}$, J. Cañavate ${ }^{1}$ and F. Carrillo ${ }^{1,2}$ \\ ${ }^{1}$ EET- Department of Chemical Engineering, Universitat Politècnica de Catalunya, \\ Colom 1, Terrassa, E - 08222, Spain. \\ ${ }^{2}$ INTEXTER, Universitat Politècnica de Catalunya, Colom 15, Terrassa, E - 08222 , \\ Spain.
}

\begin{abstract}
The study is aimed to the analysis and characterization of composites based on thermoplastics (EVA, PP and HDPE) including chicken feathers (CFs). Several composite samples with a content of $20 \%$ of CFs have been characterized in order to determinate the optimal manufacturing conditions of temperature, mixing time and mixing speed to acquire the best tensile properties. The results have shown that the addition of micronized chicken feather (20\%) to thermoplastic matrices, increases stiffness and provides a more brittle behavior. Ethylene Vinyl Acetate (EVA) matrix also shows the ability of interacting with chicken feather, thus providing better tensile properties (tensile strength and toughness) than PP and HDPE. Optimal manufacturing conditions are obtained with a mixing time around 5 minutes, a mixing speed of $50 \mathrm{rpm}$

and with a temperature values of $160^{\circ} \mathrm{C}$ HDPE, $120^{\circ} \mathrm{C}$ for EVA and $170^{\circ} \mathrm{C}$ for PP. FTIR spectroscopy and SEM micrographs analysis show results that agree with the properties obtained for the tensile properties of each one of studied composite materials.
\end{abstract}

Keywords: Chicken feathers, EVA, PP, HDPE, composites, Tensile Properties

\section{INTRODUCTION}

Nowadays, one of the greatest concerns of the humanity is the huge amounts of waste that is produced year after year around the world. There are many kinds of waste but special attention is paid to materials that are not biodegradables such as plastics or even biodegradable waste that is produced in great quantities as chicken feathers, crustacean shells. Several research groups are working with waste materials to obtain new materials with added value. In this sense, tyre rubber because of the concern of the steady increase of the production of used tyres around the world, has been 
proposed as filler or reinforcement in order to manufacture composites in thermoplastic, thermosets and rubbers matrixes [1] with interesting tensile [2-5], electrical [6-7] or acoustical properties [8-9]. Other interesting biogenic abundant and biodegradable waste are chicken feathers, that can also be a component used as reinforcement in composite materials [10-11].

Chicken feathers (CFs) are a material, constituted basically of keratin and other minoritary components [12]. Nowadays about 800,000 tons of CFs waste are produced annually in Europe [13] which are processed as a waste according to the requirements established in the European Directive [14]. This regulation permits only few uses for CFs including incineration, composting and hydrolysis for pet food production processes. These treatments transform CFs waste into materials of low added value so that the search for alternative processing method and applications, which could valorise renewable CFs waste as a second raw material, would be very interesting. In this regard, potential possible approach would be the processing of the CFs waste in order to constitute an useful technical material that could potentially be used to manufacture composites. Their unique properties such as low density, biodegradability and good thermal and acoustic properties, make them a good candidate in order to achieve materials with potential industrial applications $[10,15,16]$.

Pretreated chicken feathers (CF) have been used to manufacture composites materials with improved mechanical, thermal and acoustic properties $[11,17]$. The main issue is that properties and development of these materials are influenced by the compatibility between the composite components, since the fibre-matrix interaction can significantly influence the final macroscopic properties of the composite product. However, the combined hydrophilic and hydrophobic character of CFs resulted from their chemical nature, could be useful in order to establish the necessary interaction with polymeric matrixes. [12].

The scope of this study is to determine the optimal manufacturing conditions of temperature, mixing time and mixing speed in order to obtain the best mechanical results. Three different matrix composites (EVA, PP and HDPE) reinforced with $20 \%$ of chicken feathers has been analyzed. Mechanical and physical results of the obtained materials have been studied for under different manufacturing conditions. Spectroscopy and microscopy techniques have been used to corroborate the mechanical results and understand the chemical and morphological microstructures that are responsible for the materials behaviour. 


\section{METHODOLOGY}

\subsection{Materials}

High-density polyethylene (HDPE, ALCUDIA $® 4810-B$, Repsol, Spain) with a melt flow index of $1.35 \mathrm{~g} / \mathrm{min}$ and density of $960 \mathrm{~kg} / \mathrm{m}^{3}$,

Polypropylene (Isplen ${ }^{\circledR} 099 \mathrm{~K} 2 \mathrm{M}$, Repsol, Spain) with a melt flow index of $1.15 \mathrm{~g} / \mathrm{min}$ and density of $913 \mathrm{~kg} / \mathrm{m}^{3}$

Etthylen vinyl acetate (EVA ALCUDIA® PA 539, Repsol, Spain) with a melt flow index of $1.18 \mathrm{~g} / \mathrm{min}$ and density of $937 \mathrm{~kg} / \mathrm{m}^{3}$. CFs (Chicken feathers) were collected from a waste management Spanish company located in Catalunya.

CFs were first washed and sanitized in a bath at room temperature containing 6,75 g/l of a cationic antibacterial surfactant (Tetranyl BC-80, Kao Corporation S.A., Spain) with a 40/1 (v/w) liquor ratio for 60 minutes. After that, the CFs fibres were filtered and rinsed with deionized water and dried in an air oven at $60^{\circ} \mathrm{C}$ for $48 \mathrm{~h}$. Deionized water was used in all procedures.

To homogenize particle size, clean CFs were chopped with a mill machine (RETSCH SN 100 Germany) at a speed of $1500 \mathrm{rpm}$. until each particle size was smaller than $1000 \mu \mathrm{m}$. Finally, CFs were air-dried at $105^{\circ} \mathrm{C}$ for 4 hours and kept under dry atmosphere (dessicator) just before the compounding of the composite.

\subsection{Samples preparation}

Composite specimens were obtained by mixing the previously ground and dried CFs with HDPE, PP and EVA matrices. A unique composition has been studied: $20 \%$ fibre volume fraction $(\mathrm{v} / \mathrm{v})$, and controls of neat HDPE, PP and EVA were used as references.

The components were mixed using a Brabender mixer type W 50 EHT PL (Brabender ${ }^{\circledR}$ $\mathrm{GmbH} \& \mathrm{Co} . \mathrm{KG}$, Germany) heated at 3 different temperatures for each matrix: $170^{\circ} \mathrm{C}$, $180^{\circ} \mathrm{C}, 190^{\circ} \mathrm{C}$ for PP; $140^{\circ} \mathrm{C}, 150^{\circ} \mathrm{C}, 160^{\circ} \mathrm{C}$ for $\mathrm{HDPE}$ and $100^{\circ} \mathrm{C}, 110^{\circ} \mathrm{C}, 120^{\circ} \mathrm{C}$ for EVA, respectively and three different mixed speed, 50, 75 and $100 \mathrm{rpm}$. The HDPE, PP and EVA matrices were melted for a minute and then, the fibres were added and mixed for different periods, 5, 10 and $15 \mathrm{~min}$. 
The blend was then consolidated in a hot plates press machine type Collin Mod. P

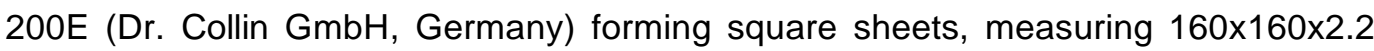
$\mathrm{mm}^{3}$. Consolidation was carried out at a pressure of $100 \mathrm{kN}$ for 5 min using temperatures of $180^{\circ} \mathrm{C}, 150^{\circ} \mathrm{C}$ and $100^{\circ} \mathrm{C}$ for PP, HDPE and EVA composites, respectively. Finally, the square sheets were cooled under pressure using cool water.

Test samples were properly shaped according to the ASTM 412 specifications to carry out tensile test measurements.

\subsection{Mechanical testing}

Tensile tests were carried out in a Instron 3366 (Instron, UK) universal machine following the specifications of the ASTM-D-638-84. Speed of the test was set at 20 $\mathrm{mm} / \mathrm{min}$ and temperature and relative humidity were $23 \pm 2{ }^{\circ} \mathrm{C}$ and $50 \pm 5 \%$, respectively. From load versus displacement test curves, Young's modulus, tensile strength, elongation at break and toughness were calculated using Bluehill version 2 software. Five replicate specimens were analysed, and average and standard deviation were calculated.

\subsection{Spectroscopic analysis}

Fourier transform infrared (FTIR) spectra were obtained by means of a Nicolet Avatar spectrometer with CsI optics. Samples of the powdered composite were ground and dispersed in a matrix of $\mathrm{KBr}$ (9 mg finely divided composite in $300 \mathrm{mg} \mathrm{KBr}$ ), followed by compression at $167 \mathrm{MPa}$ to consolidate the formation of the pellet. FTIR spectra were collected in the range of $4000-650 \mathrm{~cm}^{-1}$ with 40 scans and a resolution of $4 \mathrm{~cm}^{-1}$.

\subsection{Scanning Electron Microscopy}

Scanning Electron Microscopy (SEM) was used to qualitatively examine the fracture surface of the samples broken by the mechanical tests to study the compatibility at the GTR/PVC interface. Several images of the samples were taken in a JEOL 5610 microscope. Previously to the observations the samples were covered with a fine layer of gold-palladium in order to increase their conductivity.

\subsection{Water absorption and Dimensional Stability of composites}

Rectangular specimens $(25.4 \times 12.7 \mathrm{~mm} 2)$ with $2 \mathrm{~mm}$ thickness were conditioned in air-dried at $60^{\circ} \mathrm{C}$ for $24 \mathrm{~h}$, cooled in a desiccator and weighed $\left(\mathrm{w}_{\mathrm{o}}\right)$. Water absorption of composites was determined by immersion of the specimens in water at $25^{\circ} \mathrm{C}$ for 24 
$h$ (ASTM D570-99). Then, excess of water on the surface of the specimens was removed before weighing (w). Four specimens were tested and average and standard deviation were reported in the results section. The percentage of water absorption (WA in \%) was calculated using Eq.1:

$W A=\frac{\left(\mathrm{w}-\mathrm{w}_{\mathrm{o}}\right)}{\mathrm{w}_{\mathrm{o}}} \times 100 \quad$ Eq.1

where $w_{0}$ and $w$ represent the mass of the specimen before and after water immersion, respectively.

In addition, thickness swelling (TS in \%) of composites was calculated using Eq. 2:

$T S=\frac{\left(\varepsilon-\varepsilon_{0}\right)}{\varepsilon_{0}} \times 100 \quad E q .2$

where $\varepsilon_{0}$ and $\varepsilon$ represent the thickness of the specimen before and after the water immersion, respectively.

\section{RESULTS AND DISCUSSION}

\section{1.- Tensile properties}

Young's modulus, tensile strength, elongation at break and toughness of CF's/HDPE, CF's/PP and CF's/EVA composites at different conditions of mixing temperature, mixer blade speed and period of mixture were analyzed for a fibre volume content of $20 \%$.

As shown in table 1 the tensile properties of the HDPE/20\%CF's composite depend of mixing temperature, mixer blade speed and mixing time. Analyzing the results, it can be seen that the best performance is obtained with a mixing temperature of $160{ }^{\circ} \mathrm{C}$ for a mixing time of 5 minutes at a mixing speed of $50 \mathrm{rpm}$. Using as a reference the neat HDPE, the Young modulus increase $7.9 \%$ (from 1505 to $1624 \mathrm{MPa}$ ), the tensile strength decrease $9.6 \%$ (from 26.41 to $23.16 \mathrm{MPa}$ ), the elongation at break decrease considerably, from 296 to $6.33 \%$ and toughness decrease from 97.5 to $1.03 \mathrm{~J}$. The results of tensile strength, and specially the elongation at break and toughness using a $20 \%$ of very short chicken feathers are related to the lack of interfacial adhesion between both components due to the different chemical nature. CF's are hydrophilic compared to the highly hydrophobic nature of the HDPE. 
Table 2 shown the tensile properties of PP/20\%CF's composite. The obtained results reveal that the best performance is obtained with a mixing temperature of $170^{\circ} \mathrm{C}$ for a mixing time of 5 minutes at a mixing speed of $50 \mathrm{rpm}$. The PP matrix composite presents an analogous evolution at HDPE matrix composite. The Young modulus increase 5,6\% (from 1596 to $1682 \mathrm{MPa}$ ), and tensile strength, elongation at break and toughness decrease. Composites made with HDPE and PP behave likely because of their similar hydrophobic nature that leads to weak compatibility.

The composite EVA/CF's achieves its best performance when prepared with a mixing temperature of $120^{\circ} \mathrm{C}$ for a mixing time of 5 minutes at a mixing speed of $50 \mathrm{rpm}$. The mechanical behavior of composites EVA/CF's (table 3) is different. The increase of Young modulus is very high $1533 \%$ (from 12 to 198), the decrease of tensile strength is

higher than in case of polyolephynic matrices $65 \%$ in front of $10 \%$, although the decrease of elongation at break and toughness is higher in composites with an EVA

matrix than in those with HDPE and PP. Elongation at break decreases from 692 to $227 \%$ and toughness from 73.18 to $13.22 \mathrm{~J}$. Comparing the global results, we can conclude that EVA matrix improves the mechanical properties because of the presence of carbonyl groups, that increase the interfacial adhesion.

In all cases the optimal manufacturing conditions are obtained with a mixing time of 5 minutes and a mixing speed of $50 \mathrm{rpm}$, with at $160^{\circ} \mathrm{C}$ for HDPE, $120^{\circ} \mathrm{C}$ for EVA and $170^{\circ} \mathrm{C}$ for PP.

By using a small size of of CFs particles size (1 mm or less) and controlling the optimal temperature value for each sample a good balance between degradation and mixing is obtained.obtain. A short period of time (only 5 minutes) and low mixing speed (50 rpm) are enough to achieve the best mechanical properties.

\subsection{FTIR spectroscopic characterization}

The most representative bands of the spectra have been analyzed. The main groups assigned to the absorption bands of chicken feathers are: amide I $\left(1645 \mathrm{~cm}^{-1}\right)$ and amide II $\left(1537 \mathrm{~cm}^{-1}\right)$. Methylene $\left(1460 \mathrm{~cm}^{-1}\right)$, and methyl $\left(1378 \mathrm{~cm}^{-1}\right)$ have been assigned to polypropylene, the double methylene bands (1474 and $1464 \mathrm{~cm}^{-1}$ ) are assigned to polyethylene and finally carbonyl $\left(1755 \mathrm{~cm}^{-1}\right)$, carboxylate $\left(1253 \mathrm{~cm}^{-1}\right)$, 
methylene $\left(1465 \mathrm{~cm}^{-1}\right)$ and methyl $\left(1370 \mathrm{~cm}^{-1}\right)$ are bands assigned to ethylene vinyl acetate [18-20].

Figures 1-3 compare the spectra of EVA/CFs (Fig.1), PP/CFs (Fig. 2) and HDPE/CFs (Fig.3) composites containing $20 \%$ of CFs to the spectra of their individual components: the neat EVA, PP and HDPE matrix and pure CFs fibres. Arrows shown

in the figures point out the infrared absorption bands which present maximum absorbance shifts or variations in shape that suggest that the assigned groups are involved in the interaction between both components [21]. The differences in the environment of the groups produce a change in their frequencies of vibration. The comparative analysis of different FTIR spectra show that there is a significative difference in the maximum absorption of the bands assigned to the carbonyl group of acetate component (EVA) $\left(1755 \mathrm{~cm}^{-1}\right)$, which interacts with amine group (1537 $\left.\mathrm{cm}^{-1}\right)$

causing both groups move to higher frequency. This observation allows us to state that these two components present the best compatibility. These results are according to obtained mechanical properties of EVA/CF's, where all tensile properties were higher in value in EVA/CFs composites than in the materials obtained by the two other polyolephinic matrix.

\subsection{Scanning Electron Microscopy}

Figures 4-6 correspond to SEM micrographs of fracture surfaces of different CFs reinforced thermoplastic (EVA, PP and HDPE) composites containing $20 \%$ of chicken fibers. From the observation of the microphotographs in different magnification (EVA/CFs, PP/CFs and HDPE/CFs), it is quite clear that clearly indicate that the changes in microstructure, of do not become significant. In figures 5 and 6, (PP and

HDPE the CFs appear clean and free of any matrix material adhering to them. This is a clear indication of poor adhesion between chicken feathers fibers and polyolephinic matrix). Reinforcement adhesion seems to be better than PP and HDPE in case of EVA matrix (Figure 4). Although the picture shows there are several pullout feathers,,

some of them are coated with fragments of EVA matrix. It can be also observed that the breaking of the composites takes place by shear yield and tearing. These

differences between the failure surface of composites with different matrixes are attributed to the differences in chemical nature of the matrix that provides a different adhesion mechanism with the CFs corroborating the previous FTIR analysis. 


\subsection{Water absorption and dimensional stability of composites}

Results of water absorption of CF's/PP, CF's/HDPE and CF's/EVA composites at different conditions of mixing temperature, mixer blade speed and period of mixture were analyzed for a fibre volume content of $20 \%$. All composites showed higher water absorption than the neat matrix (PP, HDPE and EVA) due to the hydrophilic character of the chicken feather fibers used as reinforcement. However, obviously, water absorption of composites lay below the water absorption values of chicken feathers fibres (53 $\pm 4 \%$ ) themselves. Moreover, for the same volume content of CF's (20\%), some difference on water absorption was observed when using PP/HDPE or EVA matrix. For all the analyzed samples the water absorption values of CF's/EVA are higher than the obtained values for CF's/PP and CF's/HDPE. The average water absorption for CF's/EVA is $1.873 \%$ with a maximum of $2.264 \%$ and a minimum of $1.407 \%$. The average water absorption for CF's/HDPE is $0,645 \%$ with a maximum of $1.033 \%$ and a minimum of $0.373 \%$ and the average water absorption for CF's/PP is $0,476 \%$ with a maximum of $0.846 \%$ and a minimum of $0.113 \%$. The maximum of water absorption appears always whrn using the lower tested value of mixing temperature, 170 (CF's/PP), 140 (CF's/HDPE) and 100 (CF's/EVA).

In addition, an increase of the swelling thickness (dimensional stability) was observed when adding $20 \%$ of the chicken feather in the matrix of HDPE, PP and EVA.

Analyzing both results we observe a correlation between them, where the maximum and minimum of water absorption corresponds with the maximum and minimum of swelling thickness for all composites whatever the matrix (figure 7). The behavior's difference observed between both kind of matrix is due at its own nature. Ethylene

Vinyl Acetate (EVA) is more hydrophilic than polyolephinic matrices, due at the presence of ester groups with affinity with water molecules, that also produce chemical interactions with the fibers.

\section{CONCLUSION}

In order to achieve a suitable and useful biocomposite material and obtaining optimal manufacturing conditions, one of the most important aspects is the study of its behavior in terms of mechanical properties and in terms of its dimensional stability. From the study performed with chicken feather reinforced composites we can summarize that: i) the addition of micronized chicken feather to different matrices in small-middle 
quantities (20\%) as a filler, improves the stiffness and provides a more brittle behavior; ii) Ethylene Vinyl Acetate (EVA) matrix shows better mechanical properties because of the ability to interact with chicken feather, thus providing better tensile properties (tensile strength and toughness) than polyolephinic matrix; iii) optimal manufacturing conditions are obtained with a minimum mixing time ( 5 minutes) and a minimum mixing speed $(50 \mathrm{rpm})$, with a maximum value of temperature for HDPE $\left(160^{\circ} \mathrm{C}\right)$ and EVA $\left(120^{\circ} \mathrm{C}\right)$ and middle temperature value for $\mathrm{PP}\left(170^{\circ} \mathrm{C}\right)$.

By studying the FTIR spectral bands, the main results obtained were the following: i) few interactions appear between polyolephinic matrices and CF's reinforcement; ii) carbonyl group of acetate matrix component (EVA), interacts with amine group assigned to CFs reinforcement, improving the ability to establish a link between the material's components.

SEM micrographs show differences depending on the matrix used. Chemical composition in EVA defines suitable conditions to create chemical interactions and improve the compatibility with chicken feather. The fracture surfaces indicate that there is interfacial adhesion of the matrix to the chicken feather particles due mainly to the described interaction of the carbonyl group of acetate component of matrix and amine group of keratin constituent of feather. On the other hand SEM microphotographs show that polyolefinic matrices don't seem to achieve a good compatibility with CF. The results obtained for mechanical properties are justified in the light of these considerations.

According to these results, in order to achieve a better mechanical performance in terms of elongation and toughness, an EVA matrix defines the best results. The differences of the mechanical properties are attributed mainly to the chemical nature of EVA matrix compared to the chemical nature of polyolephins.

\section{ACKNOWLEDGMENTS}

Departament d'Universitats, Recerca i Societat de la Informació (DURSI) of Generalitat de Catalunya (2009SGR 1028), Spanish Ministry of Science and Innovation (MAT

2010-17057) are gratefully acknowledged. 


\section{REFERENCES}

1.- Karger-Koksis, J; Mészáros, L; Bárány, T. "Ground tyre rubber (GTR) in thermoplastics, thermosets, and rubbers" Journal of Material Science (2013) 48:138.

2.- Colom, X; Cañavate, J; Carrillo, F; Suñol, JJ." Effect of the particle size and acid pretreatments on compatibilityand properties of recycled HDPE plastic bottles filled with ground tyre powder". Journal of Applied Polymer Science (2009) 112(4):18821890.

3.- Yehia, A. ; Mull, M. A. ; Ismail, M. N. ; Hefny, Y. A. ; Abdel-Bary E. M.; "Effect of Chemically Modified Waste Rubber Powder as a Filler in Natural Rubber

Vulcanizates" Journal of Applied Polymer Science, , 2004; 93: 30-36

3.- Colom, X; Carrillo, F; Cañavate, J. composite reinforced with reused tyres: Surface oxidant treatment to improve the interfacial compatibility Composites Part A: Apllied Science and Manufacturing (2007) 38(1):44-55.

4.- Colom, X; Cañavate, J. Carrillo, F; Velasco, J.I: Pagès, P; Mujal, R; Nogués, F. "Structural and mechanical studies on modified reused tyres composites."

European polymer Journal, (2006) 42(10):2369-2378.

5.- Naskar AK, Khastgir D, Bhowmick AK and De SK. "Effect of chlorination of ground rubber tire on its compatibility with poly(vinyl chloride): dielectric studies". Journal of Applied Polymer Science (2002); 84.

6.- Mujal-Rosas, R; Marin-Genesca, M; Orrit-Prat, J; Rahhali, A; Colom, X "Dielectric, mechanical and thermal characterization of high-density polyethylene composites with ground tire rubber", Journal of Thermoplastic Composite Materials (2012) 25(5):537-559

7.- Orrit-Prat, J; Mujal-Rosas, R; Rahhali, A Marin-Genesca, M; Colom, X; Belana, J Dielectric and mechanical characterization of PVC composites with ground tire rubber, Journal of Composite Materials (2011) 45(11):1233-1243

8.- Swift, M. J., Bris, P., and Horoshenkov, K. V., , "Acoustic absorption in recycled rubber granulates," Applied Acoustics (1999) 57, 203-212.

9.- Colom, X; Cañavate, J. Carrillo, Lis, MJ. "Acustic and Mechanical properties of recycled PVC/GTR composites" accepted to be publised at Journal of Composite Materials

10.- Martínez-Hernández A.L., Velasco-Santos C., De-ICaza M., Castano V.M. "Dynamical-mechanical and thermal analysis of polymeric composites reinforced 
with keratine biofibers from chicken feathers". Composites Part B, (2007) 38: 405410.

11.- Barone, J.R. Schmidt W.F." Polyethylene reinforced with keratin fibers obtained from chicken feathers". Composite Science and Technology (2005) 62:173.

12.- Schmidt W.F., Jayasundera S. "Microcrystalline avian keratine protein fibers. In Natural Fibers, Plastics and Composites", Wallengerger F.T. and Weston N.

editors, Kluwer Academic Publishers. (2004).

13.- Data for 2010. Source: AVEC, Association of Poultry Processors and Poultry Trade in the EU countries, Annual Report 2010.

14.- European Directive CE 1069/2009.

15.- Reddy N., Yang Y. "Structure and properties of chicken feather barbs as natural protein fibers", Journal of Polymer Environment (2007). 15:81-87.

16.- Reddy N., Yang Y. "Light-Weight Polypropylene Composites Reinforced with Whole Chicken Feathers", Journal of Applied Polymer Science, (2010) 116: 36683675 .

17.- Bullions, T.A. Gillespie, R.A. Prince-O'Brien, J. Loos, A.C. "The effect of maleic anhydride modified polypropylene the mechanical properties of feathers fiber, kraft pulp, polypropylene composites". Journal of Applied Polymer Sciences (2004) 92:3771.

18.- Colom, X. Cañavate, J. Suñol, J.J. Pagés, P, Saurina, J. Carrasco, F "Natural and artificial aging of polypropylene-polyethylene copolymers" Journal of Applied

Polymer Science (2002) 87(10):1685-1692

19.- Coates, J. Interpretation of Infrared Spectra. A Practical Approach. R.A. Meyers (Ed.) John Wiley \& Sons LTD, Chichester, 2000

20.- Bower, D.I., Maddams, W.F. The vibrational spectroscopy of polymers. Cambridge Solid State Science Series. Cambridge University Press 1989

21.- Cañavate, J. Pagés, P, Saurina, J. Colom, X. Carrasco, F. "Determination of small interactions in polymer composites by means FTIR and DSC". Polymer Bulletin.

(2000), 44:293-300. 


\section{LIST OF CAPTIONS}

Table 1.- Tensile Properties of HDPE/20\%CF's composites at different conditions of mixing temperature, mixer blade speed and mixing time.

Table 2.- Tensile Properties of PP/20\%CF's composites at different conditions of mixing temperature, mixer blade speed and mixing time.

Table 3.- Tensile Properties at different conditions of mixing temperature, mixer blade speed and mixing time.

Figure 1.- Spectra of of EVA/20\%CF's composites in $1800-1100 \mathrm{~cm}^{-1}$ area: a)

CF's/EVA, b) EVA, c) CF's. Absorbance in arbitrary units.

Figure 2.- Spectra of of $P P / 20 \% C F$ 's composites in $1800-1100 \mathrm{~cm}^{-1}$ area: a)

CF's/PP, b) PP, c) CF's. Absorbance in arbitrary units.

Figure 3.- Spectra of of HDPE/20\%CF's composites in $1800-1100 \mathrm{~cm}^{-1}$ area: a) CF's/HDPE, b) HDPE, c) CF's. Absorbance in arbitrary units.

Figure 4.- SEM Microphotographs of fracture surface of CFs/EVA composite (magnification $\times 50$ )

Figure 5.- SEM Microphotographs of fracture surface of CFs/PP composite (magnification $\times 50$

Figure 6.- SEM Microphotographs of fracture surface of CFs/HDPE composite (magnification $\times 50$

Figure 7. - Water absorption and Dimensional Stability of CFs/PP, CFs/HDPE and composites 


\begin{tabular}{|c|c|c|c|c|c|c|c|c|c|}
\hline \multirow[t]{2}{*}{ Sample } & \multirow[t]{2}{*}{$\begin{array}{l}\text { Sample } \\
\text { Code }\end{array}$} & \multicolumn{2}{|c|}{$\begin{array}{c}\text { Tensile } \\
\text { Strenght } \\
(\mathrm{MPa})\end{array}$} & \multicolumn{2}{|c|}{$\begin{array}{l}\text { Young Modulus } \\
\text { (MPa) }\end{array}$} & \multicolumn{2}{|c|}{ Elongation (\%) } & \multicolumn{2}{|c|}{ Toughness (J) } \\
\hline & & Aver. & Disv & Aver. & Disv & Aver. & Disv & Aver. & Disv \\
\hline \multirow{28}{*}{ 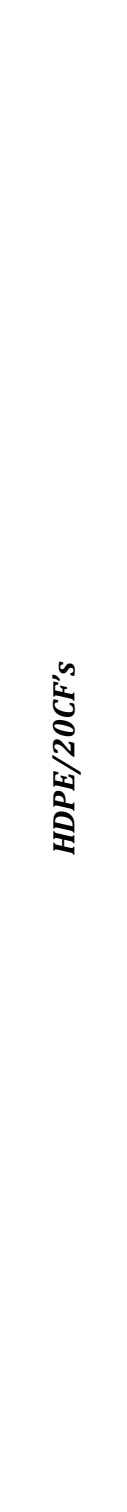 } & 140_5_50 & 22,93 & 1,54 & 1631,65 & 125,14 & 5,89 & 0,75 & 0,93 & 0,17 \\
\hline & 140_5_75 & 21,51 & 0,53 & 1532,57 & 105,76 & 5,92 & 0,90 & 0,89 & 0,17 \\
\hline & 140_5_100 & 20,85 & 1,09 & 1588,69 & 106,08 & 6,33 & 1,44 & 0,93 & 0,24 \\
\hline & 140_10_50 & 20,19 & 2,16 & 1560,01 & 118,82 & 5,16 & 0,70 & 0,72 & 0,15 \\
\hline & 140_10_75 & 20,66 & 1,85 & 1597,58 & 130,38 & 4,55 & 0,79 & 0,63 & 0,16 \\
\hline & 140_10_100 & 22,63 & 1,93 & 1643,74 & 78,98 & 3,45 & 0,35 & 0,49 & 0,09 \\
\hline & 140_15_50 & 18,51 & 1,02 & 1612,36 & 117,85 & 4,44 & 0,78 & 0,57 & 0,13 \\
\hline & 140_15_75 & 20,76 & 1,18 & 1650,92 & 55,23 & 4,70 & 0,52 & 0,67 & 0,11 \\
\hline & 140_15_100 & 20,73 & 2,02 & 1549,24 & 134,31 & 2,99 & 0,61 & 0,38 & 0,12 \\
\hline & 150_5_50 & 22,53 & 0,93 & 1629,36 & 106,13 & 5,28 & 0,74 & 0,82 & 0,16 \\
\hline & 150_5_75 & 20,92 & 1,72 & 1578,81 & 87,73 & 4,65 & 0,74 & 0,65 & 0,15 \\
\hline & 150_5_100 & 22,31 & 1,18 & 1654,66 & 81,91 & 6,17 & 1,04 & 0,97 & 0,20 \\
\hline & 150_10_50 & 20,35 & 0,79 & 1416,70 & 48,70 & 5,33 & 0,73 & 0,73 & 0,14 \\
\hline & 150_10_75 & 21,88 & 0,70 & 1475,50 & 66,71 & 4,41 & 0,28 & 0,62 & 0,06 \\
\hline & 150_10_100 & 21,39 & 0,52 & 1592,71 & 120,04 & 3,67 & 0,42 & 0,50 & 0,07 \\
\hline & 150_15_50 & 18,81 & 1,10 & 1515,77 & 92,81 & 4,41 & 0,58 & 0,57 & 0,12 \\
\hline & 150_15_75 & 21,37 & 1,77 & 1517,94 & 114,53 & 4,27 & 0,53 & 0,60 & 0,09 \\
\hline & 150_15_100 & 21,63 & 1,11 & 1787,80 & 137,73 & 4,55 & 0,75 & 0,68 & 0,15 \\
\hline & 160_5_50 & 23,16 & 1,36 & 1624,33 & 43,42 & 6,33 & 1,03 & 1,03 & 0,23 \\
\hline & 160_5_75 & 22,95 & 1,13 & 1674,65 & 60,23 & 6,06 & 0,53 & 0,97 & 0,10 \\
\hline & 160_5_100 & 19,36 & 1,40 & 1534,54 & 66,58 & 4,50 & 0,91 & 0,59 & 0,18 \\
\hline & 160_10_50 & 18,94 & 0,72 & 1447,46 & 87,08 & 5,26 & 0,74 & 0,69 & 0,11 \\
\hline & 160_10_75 & 20,84 & 0,62 & 1499,25 & 90,00 & 4,69 & 0,77 & 0,66 & 0,14 \\
\hline & 160_10_100 & 20,21 & 0,89 & 1661,43 & 130,62 & 4,69 & 1.02 & 0,67 & 0,20 \\
\hline & 160_15_50 & 19,87 & 1,40 & 1524,58 & 107,33 & 4,72 & 0,37 & 0,64 & 0,04 \\
\hline & 160_15_75 & 19,67 & 0,86 & 1525,14 & 53,76 & 3,59 & 0,29 & 0,46 & 0,06 \\
\hline & 160_15_100 & 20,62 & 0,19 & 1539,16 & 77,97 & 7,37 & 0,80 & 1,08 & 0,17 \\
\hline & $H D P E$ & 26,41 & 0,31 & 1505,76 & 51,76 & 297,17 & 94,45 & 44,29 & 14,05 \\
\hline
\end{tabular}

Table 1 


\begin{tabular}{|c|c|c|c|c|c|c|c|c|c|}
\hline \multirow{2}{*}{ Sample } & \multirow{2}{*}{ Simple code } & \multicolumn{2}{|c|}{$\begin{array}{c}\text { Tensile } \\
\text { Strength (MPa) }\end{array}$} & \multicolumn{2}{|c|}{$\begin{array}{l}\text { Young Modulus } \\
(\mathrm{MPa})\end{array}$} & \multicolumn{2}{|c|}{ Elongation (\%) } & \multicolumn{2}{|c|}{ Toughness (J) } \\
\hline & & Aver & Disv & Aver & Disv & Aver & Disv & Aver & Disv \\
\hline \multirow{19}{*}{ 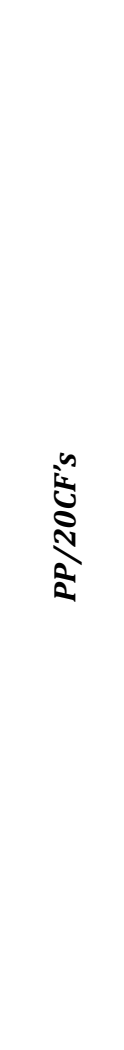 } & 170_5_50 & 22,70 & 0,95 & 1682,18 & 58,74 & 9,71 & 2,06 & 1,67 & 0,37 \\
\hline & 170_5_75 & 21,58 & 1,89 & 1704,89 & 53,63 & 5,32 & 1,03 & 0,82 & 0,21 \\
\hline & 170_5_100 & 20,36 & 1,56 & 1749,36 & 32,68 & 4,98 & 1,06 & 0,73 & 0,20 \\
\hline & 170_10_50 & 23,27 & 1,19 & 1684,41 & 44,93 & 8,94 & 1,37 & 1,58 & 0,28 \\
\hline & 170_10_75 & 21,25 & 0,68 & 1559,76 & 41,45 & 10,31 & 3,44 & 1,71 & 0,64 \\
\hline & 170_10_100 & 19,95 & 0,67 & 1608,94 & 48,99 & 3,47 & 0,52 & 0,46 & 0,09 \\
\hline & 170_15_50 & 20,10 & 0,86 & 1763,49 & 60,47 & 4,35 & 1,04 & 0,61 & 0,20 \\
\hline & 170_15_75 & 19,51 & 1,06 & 1763,86 & 44,81 & 7,05 & 1,20 & 1,06 & 0,23 \\
\hline & 170_15_100 & 19,67 & 0,41 & 1721,68 & 51,75 & 8,54 & 1,60 & 1,32 & 0,28 \\
\hline & 180_5_50 & 23,62 & 0,75 & 1743,42 & 59,52 & 6,81 & 1,34 & 1,16 & 0,26 \\
\hline & 180_5_75 & 22,99 & 1,23 & 1699,48 & 81,82 & 5,73 & 0,91 & 0,93 & 0,21 \\
\hline & 180_5_100 & 18,94 & 0,27 & 158,24 & 48,57 & 4,65 & 0,73 & 0,62 & 0,11 \\
\hline & 180_10_50 & 18,99 & 1,16 & 1675,82 & 47,17 & 3,88 & 0,72 & 0,51 & 0,12 \\
\hline & 180_10_75 & 18,43 & 0,47 & 1629,14 & 41,87 & 15,40 & 6,05 & 2,35 & 0,98 \\
\hline & 180_10_100 & 19,33 & 0,55 & 1659,05 & 85,75 & 23,73 & 5,53 & 3,82 & 0,96 \\
\hline & 190_5_50 & 22,07 & 1,39 & 1718,48 & 74,17 & 7,07 & 1,49 & 1,12 & 0,27 \\
\hline & 190_5_75 & 20,96 & 1,16 & 1536,01 & 24,11 & 5,27 & 0,98 & 0,77 & 0,17 \\
\hline & 190_5_100 & 20,97 & 0,14 & 1580,38 & 41,42 & 9,18 & 1,92 & 1,48 & 0,33 \\
\hline & $P P$ & 37,34 & 4,97 & 1596,71 & 146,95 & 436,62 & 60,73 & 102,79 & 22,36 \\
\hline
\end{tabular}

Table 2 


\begin{tabular}{|c|c|c|c|c|c|c|c|c|c|}
\hline \multirow[t]{2}{*}{ Sample } & \multirow[t]{2}{*}{$\begin{array}{l}\text { Sample } \\
\text { Code }\end{array}$} & \multicolumn{2}{|c|}{$\begin{array}{c}\text { Tensile } \\
\text { Strenght } \\
(\mathrm{MPa})\end{array}$} & \multicolumn{2}{|c|}{$\begin{array}{l}\text { Young Modulus } \\
(\mathrm{MPa})\end{array}$} & \multicolumn{2}{|c|}{ Elongation (\%) } & \multicolumn{2}{|c|}{ Toughness (J) } \\
\hline & & Aver. & Disv & Aver. & Disv & Aver. & Disv & Aver. & Disv \\
\hline \multirow{28}{*}{ 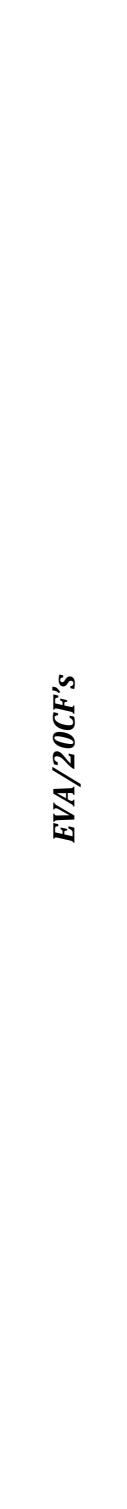 } & 100_5_50 & 6,71 & 0,68 & 195,36 & 4,18 & 179,40 & 62,67 & 9,48 & 3,68 \\
\hline & 100_5_75 & 7,17 & 0,85 & 176,08 & 25,18 & 213,04 & 40,99 & 11,70 & 3,21 \\
\hline & 100_5_100 & 7,37 & 0,46 & 190,87 & 25,23 & 229,95 & 15,71 & 12,84 & 1,42 \\
\hline & 100_10_50 & 6,86 & 0,60 & 154,94 & 12,79 & 215,47 & 31,64 & 11,04 & 2,21 \\
\hline & 100_10_75 & 7,19 & 0,44 & 160,88 & 16,56 & 226,11 & 13,24 & 12,20 & 1,16 \\
\hline & 100_10_100 & 6,60 & 0,29 & 159,11 & 8,47 & 191,52 & 30,83 & 9,89 & 1,76 \\
\hline & 100_15_50 & 6,67 & 0,52 & 150,1 & 11,03 & 200,46 & 36,76 & 10,07 & 2,51 \\
\hline & 100_15_75 & 6,90 & 0,90 & 152,93 & 11,91 & 209,26 & 31,20 & 11,02 & 2,70 \\
\hline & 100_15_100 & 6,98 & 0,16 & 151,16 & 7,77 & 178,17 & 5,20 & 9,90 & 0,32 \\
\hline & 110_5_50 & 6,30 & 0,19 & 148,77 & 16,98 & 200,46 & 36,76 & 9,62 & 1,71 \\
\hline & 110_5_75 & 6,72 & 0,26 & 164,82 & 17,26 & 214,51 & 11,36 & 10,99 & 0,31 \\
\hline & 110_5_100 & 7,27 & 0,63 & 180,88 & 21,81 & 198,24 & 20,55 & 11,13 & 2,08 \\
\hline & 110_10_50 & 7,42 & 0,29 & 173,69 & 14,94 & 221,85 & 11,69 & 12,37 & 0,83 \\
\hline & 110_10_75 & 7,23 & 0,19 & 175,08 & 15,56 & 191,59 & 27,25 & 10,84 & 1,58 \\
\hline & 110_10_100 & 6,62 & 0,65 & 157,28 & 18,10 & 180,70 & 33,22 & 9,47 & 2,60 \\
\hline & 110_15_50 & 7,27 & 0,48 & 166,45 & 18,22 & 201,64 & 26,03 & 11,42 & 2,02 \\
\hline & 110_15_75 & 6,97 & 0,49 & 170,24 & 14,13 & 112,25 & 36,74 & 6,22 & 1,80 \\
\hline & 110_15_100 & 6,89 & 0,38 & 157,04 & 18,73 & 98,78 & 35,41 & 5,42 & 1,78 \\
\hline & 120_5_50 & 7,71 & 0,95 & 197,98 & 30,79 & 227,24 & 22,23 & 13,22 & 2,76 \\
\hline & 120_5_75 & 7,74 & 0,27 & 175,41 & 9,88 & 225,90 & 17,38 & 13,33 & 1,32 \\
\hline & 120_5_100 & 7,03 & 0,31 & 168,75 & 6,56 & 182,86 & 24,56 & 10,24 & 1,50 \\
\hline & 120_10_50 & 6,70 & 0,42 & 163,98 & 8,19 & 214,76 & 24,43 & 11,29 & 1,23 \\
\hline & 120_10_75 & 6,15 & 0,36 & 156,53 & 4,34 & 140,84 & 37,14 & 7,19 & 2,27 \\
\hline & 120_10_100 & 7,28 & 0,40 & 165,89 & 9,12 & 53,54 & 17,76 & 3,02 & 1.03 \\
\hline & 120_15_50 & 6,50 & 0,31 & 162,92 & 6,65 & 120,35 & 30,56 & 6,41 & 1,91 \\
\hline & 120_15_75 & 6,91 & 0,72 & 157,46 & 16,11 & 76,10 & 28,26 & 4,09 & 1,57 \\
\hline & 120_15_100 & 7,88 & 0,73 & 162,8 & 11,43 & 34,55 & 13,47 & 1,93 & 0,77 \\
\hline & 5_100_50 & 22,66 & 1,50 & 12,06 & 3,23 & 692,10 & 57,97 & 73,18 & 12,22 \\
\hline
\end{tabular}

Table 3 


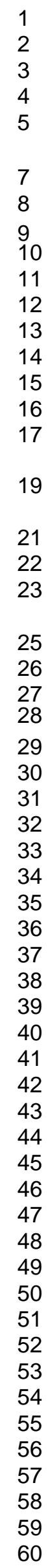

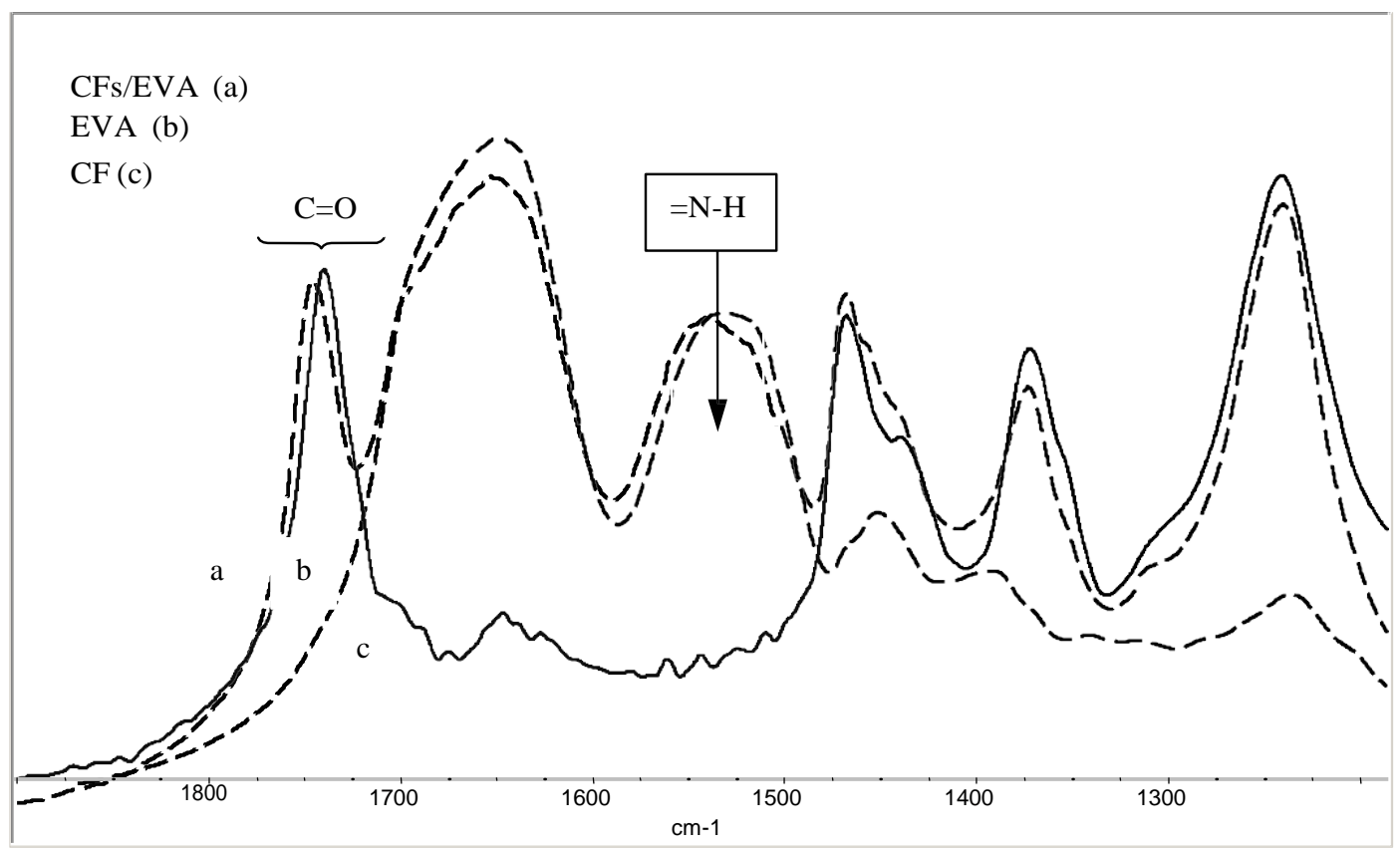

Figure 1.- 
\begin{tabular}{l}
1 \\
2 \\
3 \\
4 \\
5 \\
6 \\
7 \\
8 \\
9 \\
10 \\
11 \\
12 \\
13 \\
14 \\
15 \\
16 \\
17 \\
18 \\
19 \\
20 \\
21 \\
22 \\
23 \\
24 \\
25 \\
26 \\
27 \\
28 \\
29 \\
30 \\
31 \\
32 \\
33 \\
34 \\
35 \\
36 \\
37 \\
38 \\
39 \\
40 \\
41 \\
42 \\
43 \\
44 \\
45 \\
46 \\
47 \\
48 \\
49 \\
50 \\
51 \\
52 \\
53 \\
55 \\
5 \\
\hline
\end{tabular}

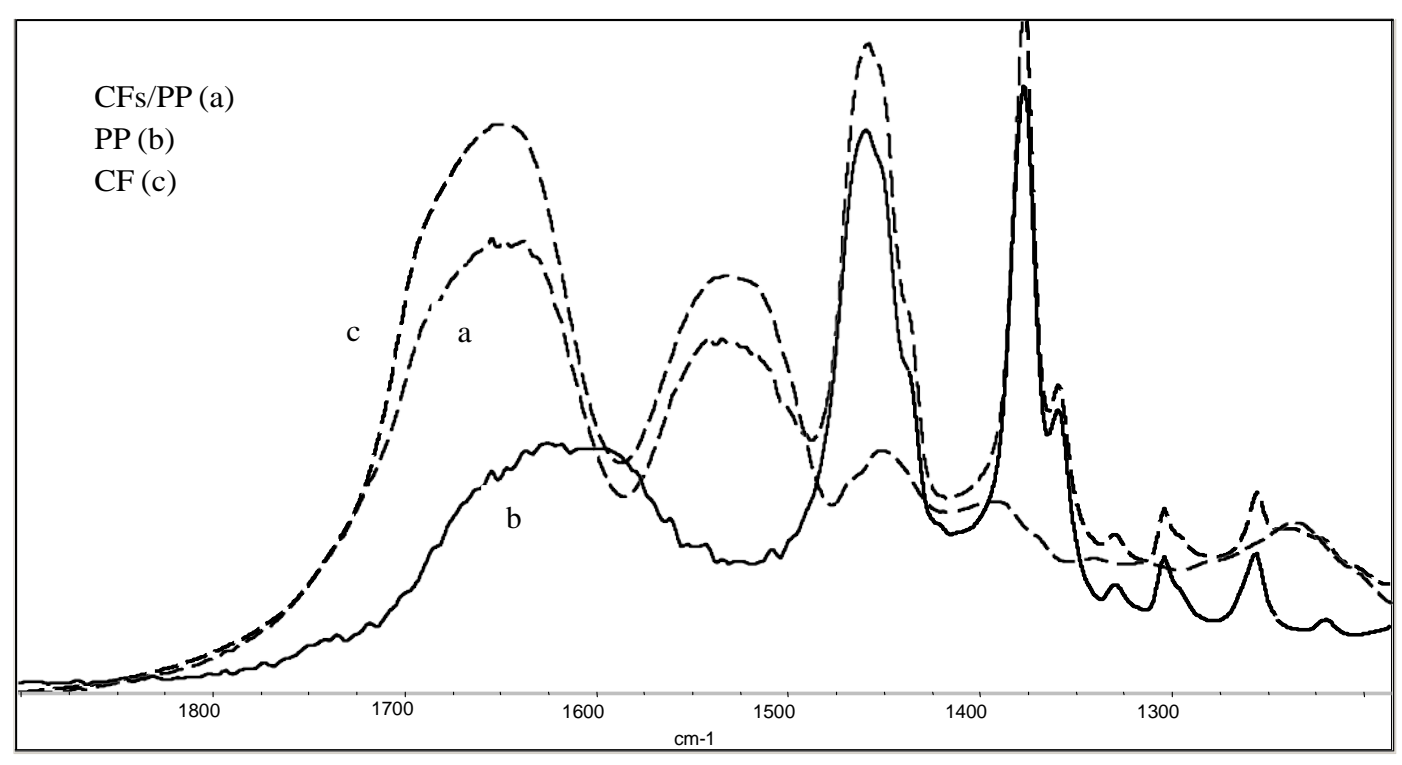

Figure 2.- 


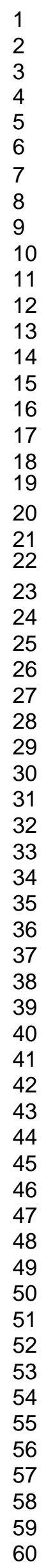

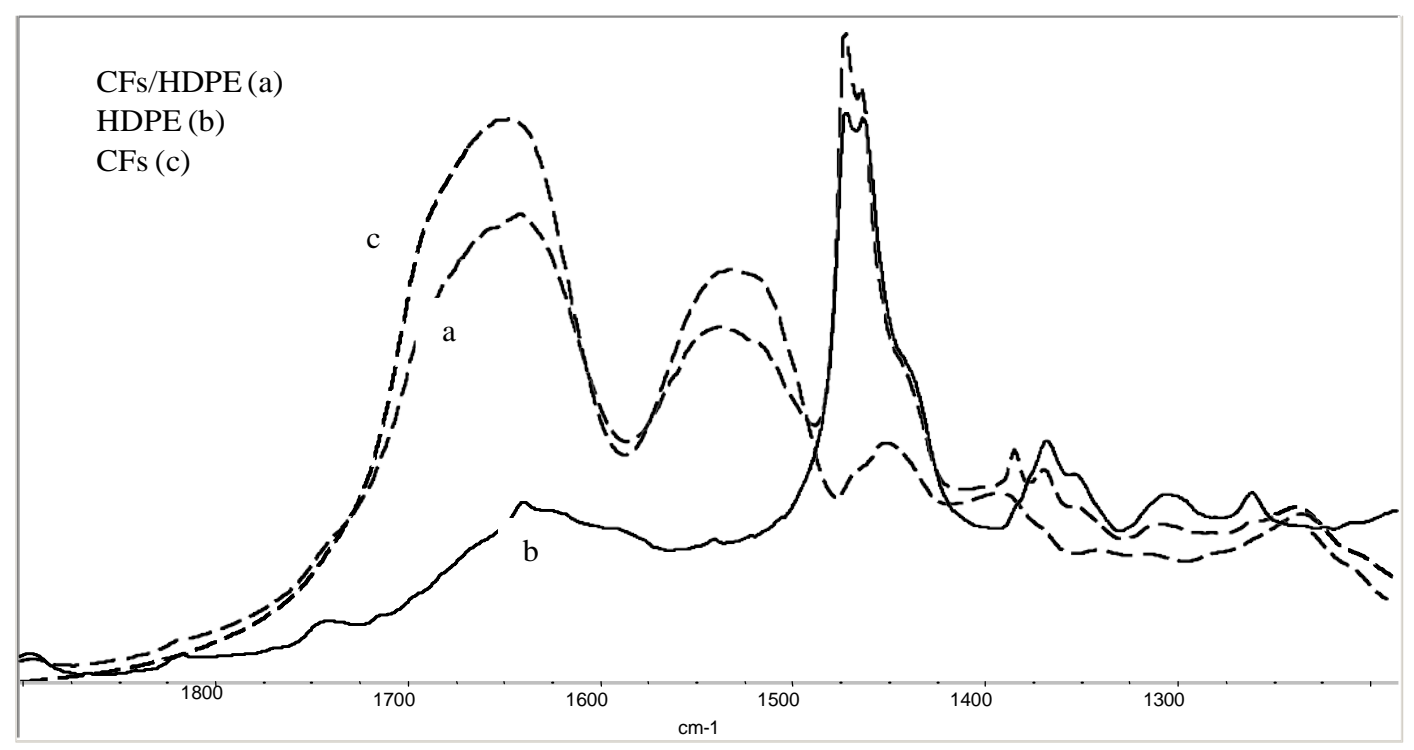

Figure 3 
Figure 7 


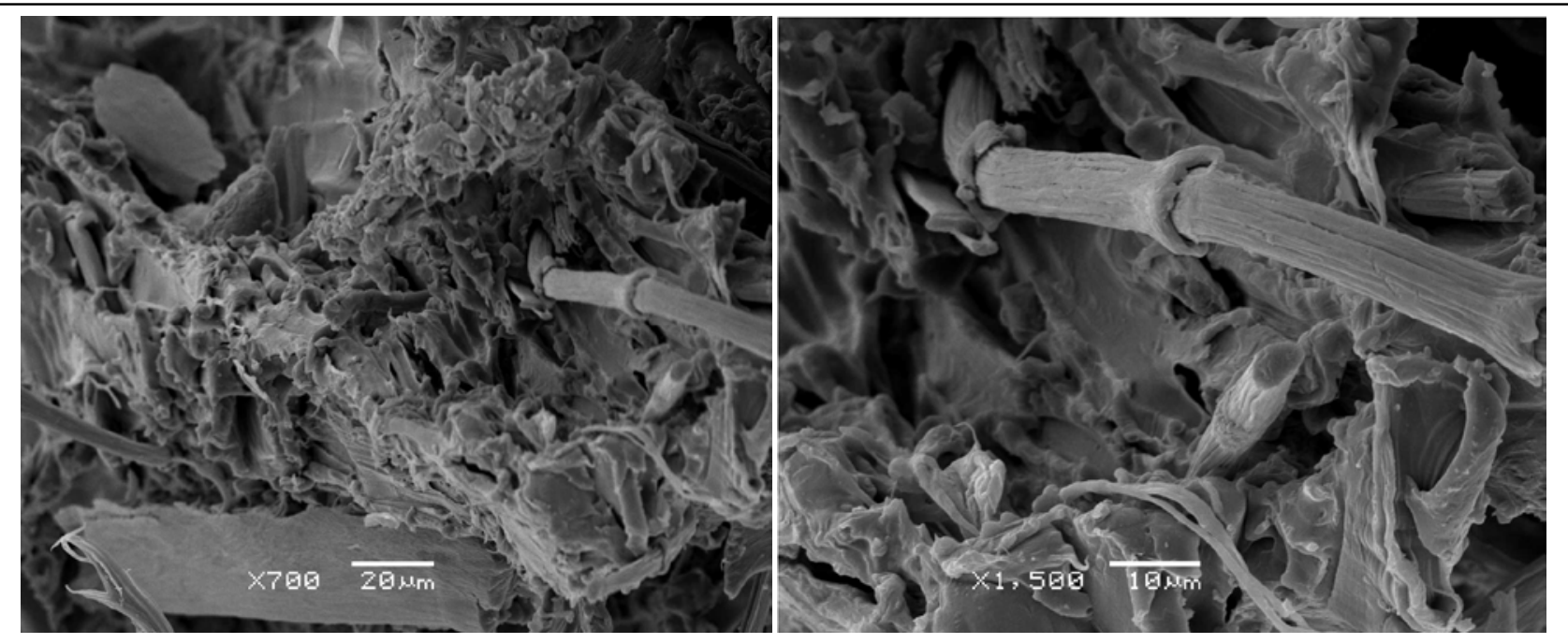

Figure 4

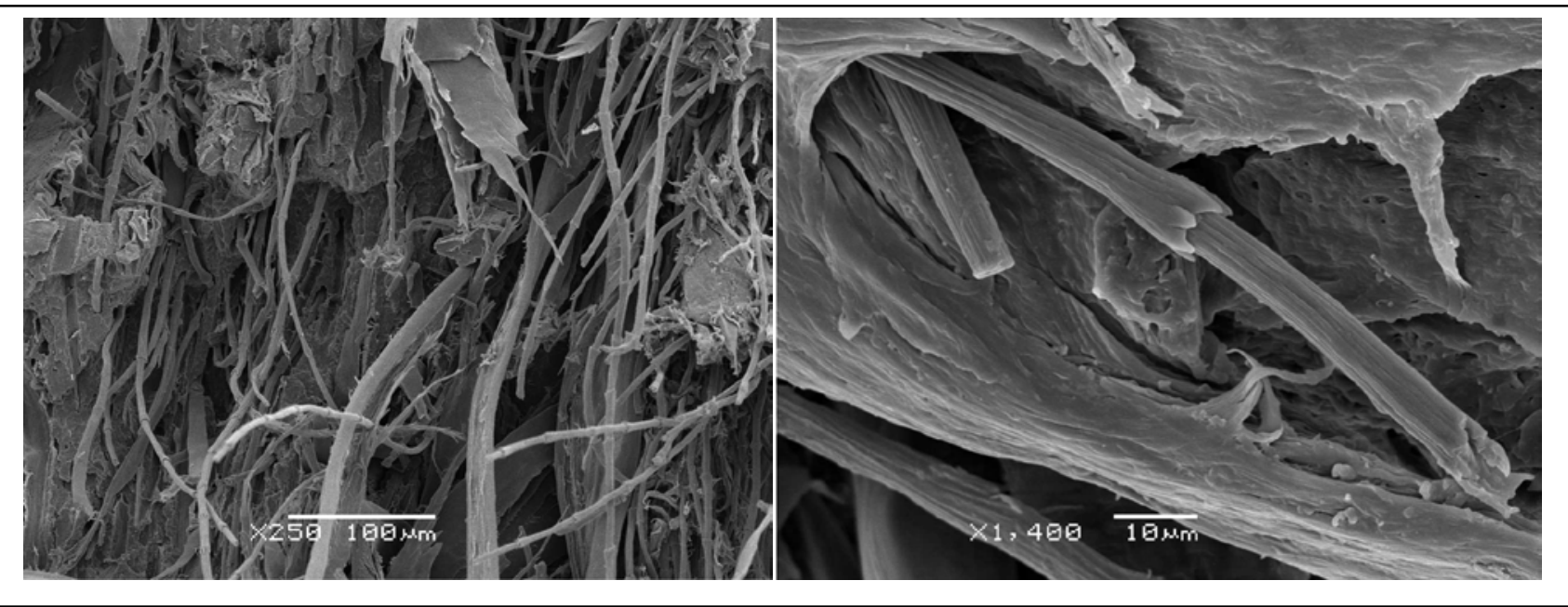

\section{Figure 5}

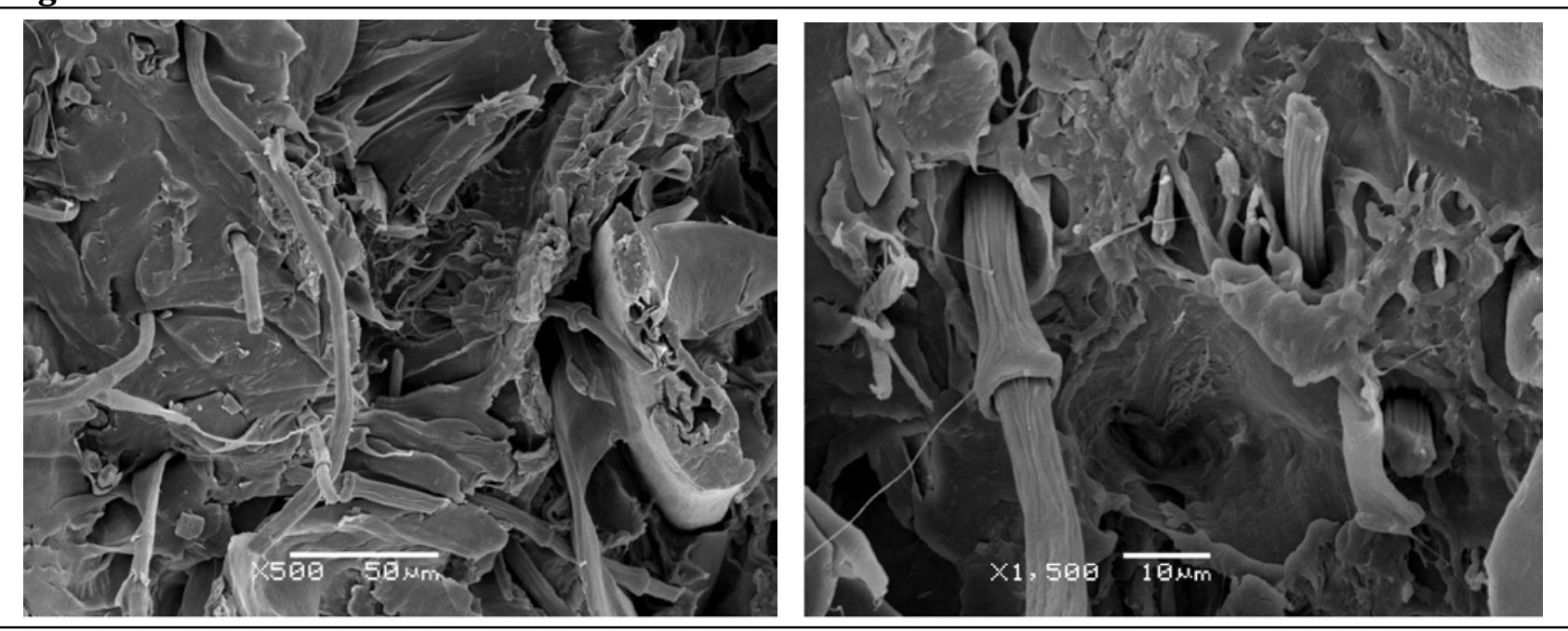

Figura 6 
